А. А. Барон, Л. В. Палаткина, С. В. Палаткин

КОМПЬЮТЕРНОЕ МОДЕЛИРОВАНИЕ ПРОЦЕССА ЗАПОЛНЕНИЯ РАСПЛАВОМ ПЕСЧАНОЙ ФОРМЫ ДЛЯ ПОЛУЧЕНИЯ ЗАГОТОВОК СТАНДАРТНЫХ РАЗРЫВНЫХ ОБРАЗЦОВ ЧУГУНА

Волгоградский государственный технический университет e-mail: a_baron@mail.ru, lv.palatkina@yandex.ru

Визуализация процесса заполнения формы в среде программного комплекса LVMFlow позволила выявить характерные особенности заполнения расплавом серого чугуна песчаной формы для получения заготовок стандартных разрывных образцов.

Ключевые слова: серый чугун, компьютерное моделирование, заполнение песчаной формы расплавом, гидравлические потоки и конвективные скорости.

A. A. Baron, L. V. Palatkina, S. V. Palatkin

\title{
COMPUTER SIMULATION OF FILLING SAND MOLD PROCESS WITH MELT FOR BLANKS OF STANDARD TENSILE SAMPLES OF CAST IRON PRODUCTION
}

\section{Volgograd State Technical University}

Visualization of the mold filling process in the environment of the LVMFlow software complex made it possible to identify the characteristic features of filling sand-shaped grey cast iron with melt to obtain samples for testing mechanical properties.

Keywords: grey cast iron, computer simulation, filling the sand mold with melt, hydraulic flows and convective velocities.

(C Барон А. А., Палаткина Л. В., Палаткин С. В., 2021 


\section{Введение}

Для серого чугуна в соответствии с ГОСТ 24648-90 [1] литая проба определяет марку и качество заливаемых одновременно с ней отливок ответственного назначения. При прочих равных условиях, проба должна обеспечить для каждого образца: структуру, идентичную структуре конечного литого изделия; стабильность свойств в объеме; отсутствие дефектов усадочного происхождения в зоне предполагаемого разрушения (шейка образца). С целью получения литой пробы заготовок образцов для испытания на растяжение серого чугуна с пластинчатым графитом, согласно ГОСТ 16818-85 [2], используется форма песчаная, заполняемая сифонным способом.

Следует отметить, что на сегодняшний момент в литературе не содержится информации о процессах, протекающих при заполнении песчаной формы и особенностях кристаллизации расплава в процессе получения литых заготовок образцов для испытаний серого чугуна на растяжение. Это обусловлено не только отсутствием возможности визуального наблюдения за заполнением чугунным расплавом песчаной формы при сифонным способе заливки в реальных условиях, но и отсутствием (для реализации физического моделирования) модельного расплава вещества, кристаллизующегося с аналогичной чугуну сменой механизмов роста твердой фазы (дендритная и последующая эвтектическая кристаллизация). На практике в условиях производства это может приводить к ряду отклонений при определении марки и качества заливаемых одновременно с пробой чугунных отливок.

Ранее опубликованные в работе [3] результаты нашего исследования впервые показали возможность использования программного комплекса LVMFlow для компьютерного моделирования процессов заливки и затвердевания стандартной литой пробы серого чугуна. Данные о расположении дефектов усадочного происхождения, полученные путем компьютерного моделирования, были подтверждены результатами фрактографических и металлографических исследований чугунов, выплавленных по штатной технологии в производственных условиях литейного цеха.

Цель данной работы заключалась в исследовании с помощью компьютерного моделирования процессов, протекающих при сифонном способе заливки формы для получения заготовок стандартных разрывных образцов чугуна.

\section{Материалы и методы исследования}

В среде программного комплекса Solid Works по размерам чертежа песчаной формы для получения заготовок стандартных разрывных образцов ГОСТ 16818-85 [2] была создана 3D-модель литой пробы (рис. 1, a) [3].

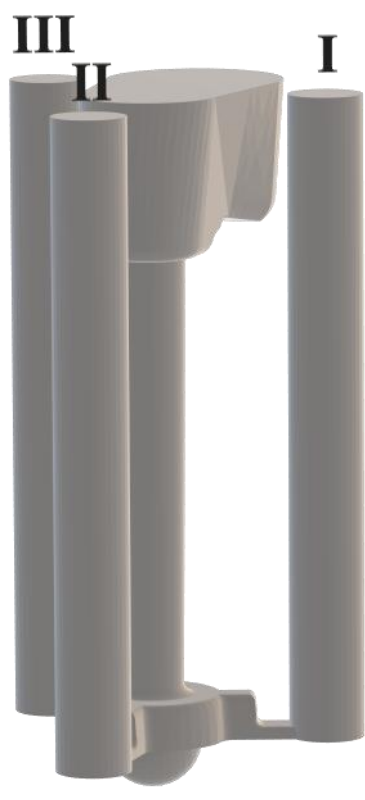

$a$

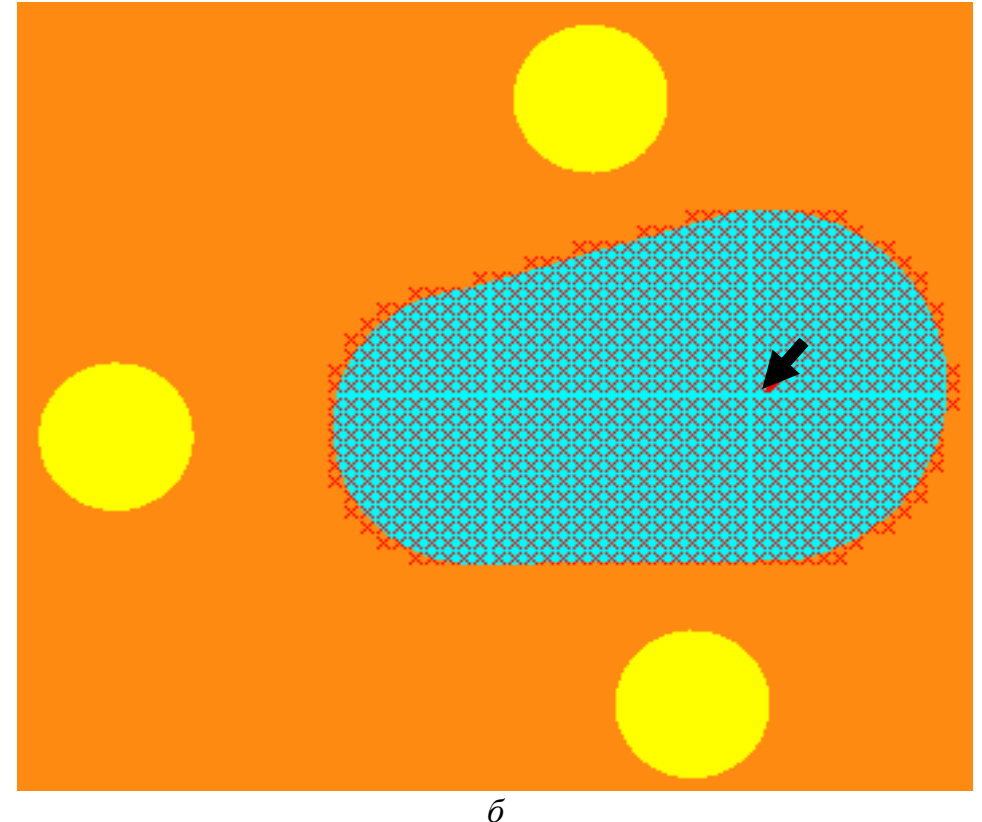

6

Рис. 1. Исходные данные для построения модели:

$a$ - 3D-модель литой пробы: $I$ - заготовка для первого образца; $I I$ - заготовка для второго образца; $I I I$ - заготовка для третьего образца; $\sigma$ - задание литниковой точки (место ввода расплава в объем литниковой чаши указано стрелочкой) 
Дале для спроектированной 3D-модели литой пробы в среде программного комплекса системы моделирования LVMFlow (программа предоставлена ЗАО НПО «МКМ», № версии 4.4r6 Time, № лицензии Т0027) создавалась задача на основе следующих исходных данных:

1. На основе используемого в LVMFlow метода контрольных объемов [4] определялись параметры сеточной модели и соответственно точность моделирования, за счет выбора размера ячейки (3 мм) и размера расчетной области с заданием положения отливки.

2. Производилось задание литниковой точки - точки ввода расплава в объем литниковой чаши (рис. 1, б). Ее координаты выбирались в соответствии с формой дна литниковой чаши и на основе анализа выбора оптимального положения, произведенного на базе нескольких вариантов моделирования в соответствии с основными положениями, учитывающими поступление расплава в стояк и циркуляцию металла в чаше $[6,7]$. При этом система автоматически подбирает: угол вхождения струи в форму равным $15^{\circ}$ и высоту ковша над чашей как расстояние от верхней кромки верхней опоки до уровня зеркала металла в ковше.

3. Выбирался тип материала формы (песчаная смесь) и модельного расплава (серый чугун с пластинчатым графитом марки СЧ 20 (см. таблицу).

Основные данные о композициях чугуна, использованных для моделирования

\begin{tabular}{|c|c|c|c|c|c|c|c|}
\hline \multirow{2}{*}{ Марка } & \multirow{2}{*}{$\begin{array}{c}\text { Предел } \\
\text { прочности } \\
\sigma_{\mathrm{B}}, \mathrm{MПа} \\
\end{array}$} & \multirow{2}{*}{$\begin{array}{c}\text { Твердость } \\
\text { по Бринеллю } \\
\text { НВ }\end{array}$} & \multicolumn{5}{|c|}{ Содержание основных элементов, \% масс } \\
\hline & & & $\mathrm{C}$ & $\mathrm{Si}$ & $\mathrm{Mn}$ & $\mathrm{P}$ & S \\
\hline СЧ $20 *$ & 200 & 202 & 3,18 & 1,51 & 0,78 & 0,05 & 0,05 \\
\hline СЧ20* & 200 & 217 & 3,52 & 2,24 & 0,79 & 0,05 & 0,14 \\
\hline СЧ $20 * *$ & 200 & 230 & 3,30 & 1,40 & 0,70 & 0,20 & 0,15 \\
\hline СЧ $20 * *$ & 200 & 230 & 3,50 & 2,40 & 1,00 & 0,20 & 0,15 \\
\hline
\end{tabular}

* Выплавлены по штатной технологии в производственных условиях литейного цеха в соответствии с $[1,2,5]$.

** Нижний и верхний пределы содержания основных элементов по ГОСТ 1412-85 [5].

4. В соответствии с ГОСТ 16818-85 [2] форма перед заливкой должна иметь температуру от $15{ }^{\circ} \mathrm{C}$ до $35{ }^{\circ} \mathrm{C}$, поэтому для моделирования была задана начальная температура формы $20^{\circ} \mathrm{C}$. Кроме этого, сухая форма должна быть окрашена противопригарным покрытием для чугунных отливок; этот параметр также был задан при определении задачи моделирования.

5. Заливка формы осуществлялась из литейного ковша диаметром струи 18 мм со скоростью, обусловленной массой и используемым для заливки отливки сифонным способом. Начальная температура расплава $\left(1400{ }^{\circ} \mathrm{C}\right)$ выбиралась исходя из стандартных условий, используемых при разливке тонкостенных чугунных отливок [6].

6. При моделировании в программе LVMFlow в режиме отображения 3D в различных сечениях формы и заготовок образцов оценивали: в зависимости от объема жидкой фазы, характер заполнения песчаной формы (отдельно для объема литниковой чаши, стояка и заготовок образцов); изменение направлений индикаторов скорости течения расплава (на характерных этапах последовательного заполнения и после- дующего образования конвективных потоков); изменение температуры расплава в период заполнения формы.

\section{Результаты и их обсуждение}

Характерные этапы последовательного заполнения расплавом песчаной формы, выделенные по результатам анализа моделирования, проведенного в режиме отображения «прозрачная модель», показаны на рис. 2.

Первые порции расплава поступают в литниковую чашу в виде компактной струи с близким к кругу сечением, по траектории, рассчитываемой программой самостоятельно на основе заданных параметров заливки. При 8-10\% жидкой фазы, заполнившей общий объем формы, металл начинает поступать из объема литниковой чаши в вертикальный стояк, постепенно стекая в нижнюю часть формы (центральная область литникового хода) преимущественно по одной из его стенок. Далее, при содержании в объеме формы 25-30 \% расплава, наблюдается этап равномерного заполнения и последующего подъема жидкой фазы во всех заготовках образцов; при этом в начальный момент посту- 
пления первых порций расплава (в эти части формы) могут наблюдаться заплески расплава. Последние с потерей напора струи и по мере подъема уровня жидкости исчезают. Также следует отметить, что только при 40-45 \% объема жидкой фазы струя расплава в стояке полностью заполняет его поперечное сечение по всей длине.

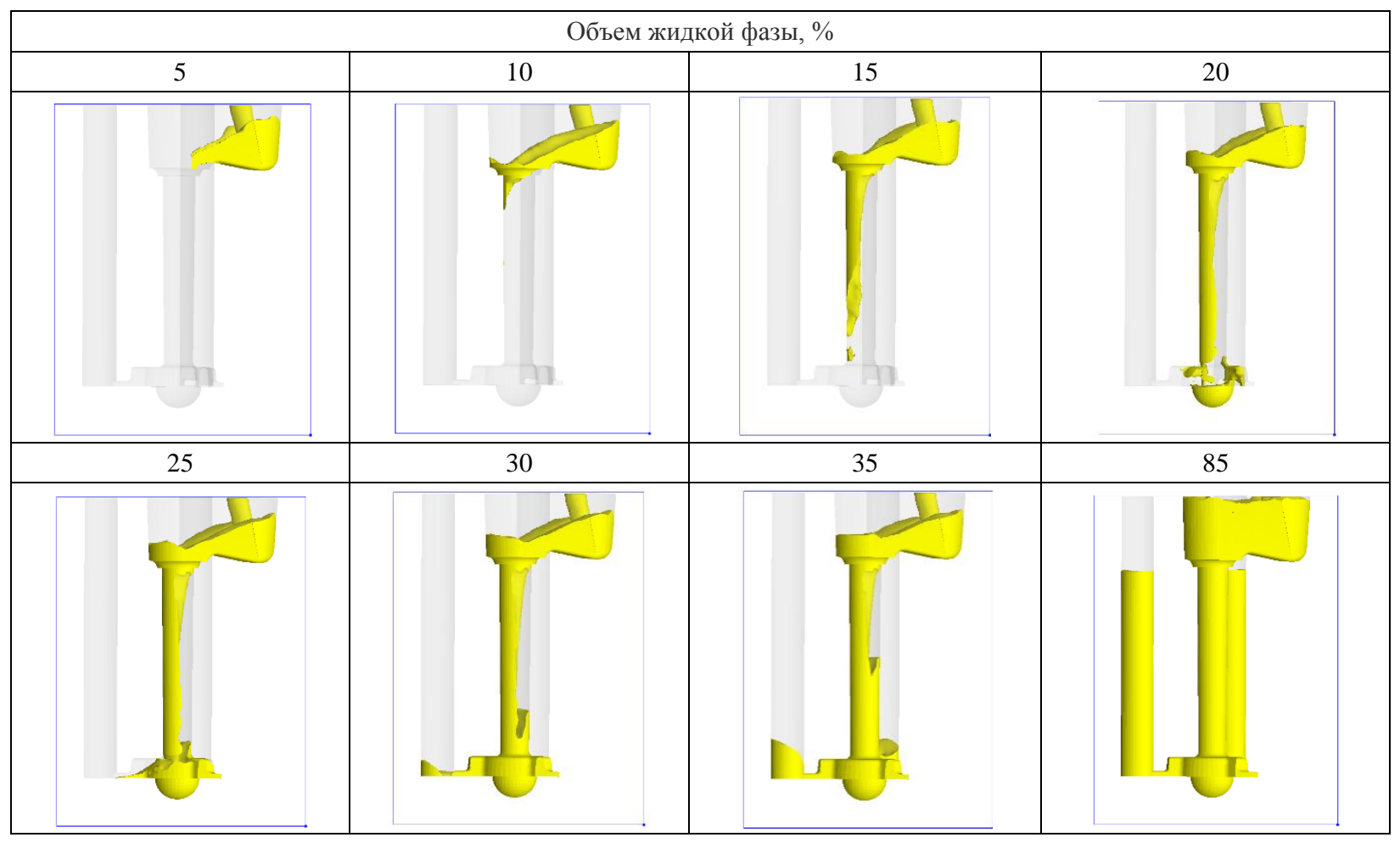

Рис 2. Характерные этапы последовательного заполнения расплавом песчаной формы в зависимости от объема жидкой фазы, указанной в процентах (моделирование в режиме отображения «прозрачная модель» в сечении литниковой чаши и заготовок для образца II и III)

В первый момент подачи расплавленного металла в литниковую чашу из разливочного ковша кинетическая энергия струи жидкой фазы значительно снижается за счет ее гашения о дно. По мере увеличения объема жидкой фазы в литниковой чаше происходит перетекание расплава через ее порог, при этом в движущемся расплаве наблюдается образование двух динамических областей с разной средней скоростью потока 0,8 и 1,3 см/с (рис. 3). Образование таких незначительных завихрений расплава создает благоприятные условия для всплытия шлака и более равномерного заполнения расплавом, свободным от посторонних примесей, стояка и формы.

Начиная с момента, при котором в объеме формы фиксируется 15-18 \% жидкой фазы, а струя расплава достигает дна литникового хода (с увеличением скорости течения до 2,6$2,9 \mathrm{~cm} / \mathrm{c})$, в ней наблюдается образование областей, ограниченных изолинией, в каждой точке которой величина скорости сохраняет одинаковое значение. Область с равной скоростью течения расплава $(2,0$ cм/c), ограниченная изолинией, сохраняется вплоть до 35-40 \% заполнения объема жидкой фазой (рис. 3, a) и фиксируется только в стояке формы.

Визуализация процесса заполнения объемов заготовок образцов (рис. 3, б) показала, что жидкая фаза течет в их объеме по режиму, приближенному к ламинарному (без значительного перемешивания и образования турбулентных потоков с завихрениями). При этом цветовая идентификация гидравлических потоков в продольном сечении показала схожие распределения скоростей для всех заготовок образцов: у зеркала металла скорость не превышала $0,2 \mathrm{~cm} / \mathrm{c}$, а в нижней части максимальные значения фиксировали на уровне $1,8 \mathrm{~cm} / \mathrm{c}$.

После полного заполнения формы программа LVMFlow автоматически переходит к модулю «Конвективные скорости, см/с» для моделирования конвективных потоков, формируемых на основе гидравлических потоков. 


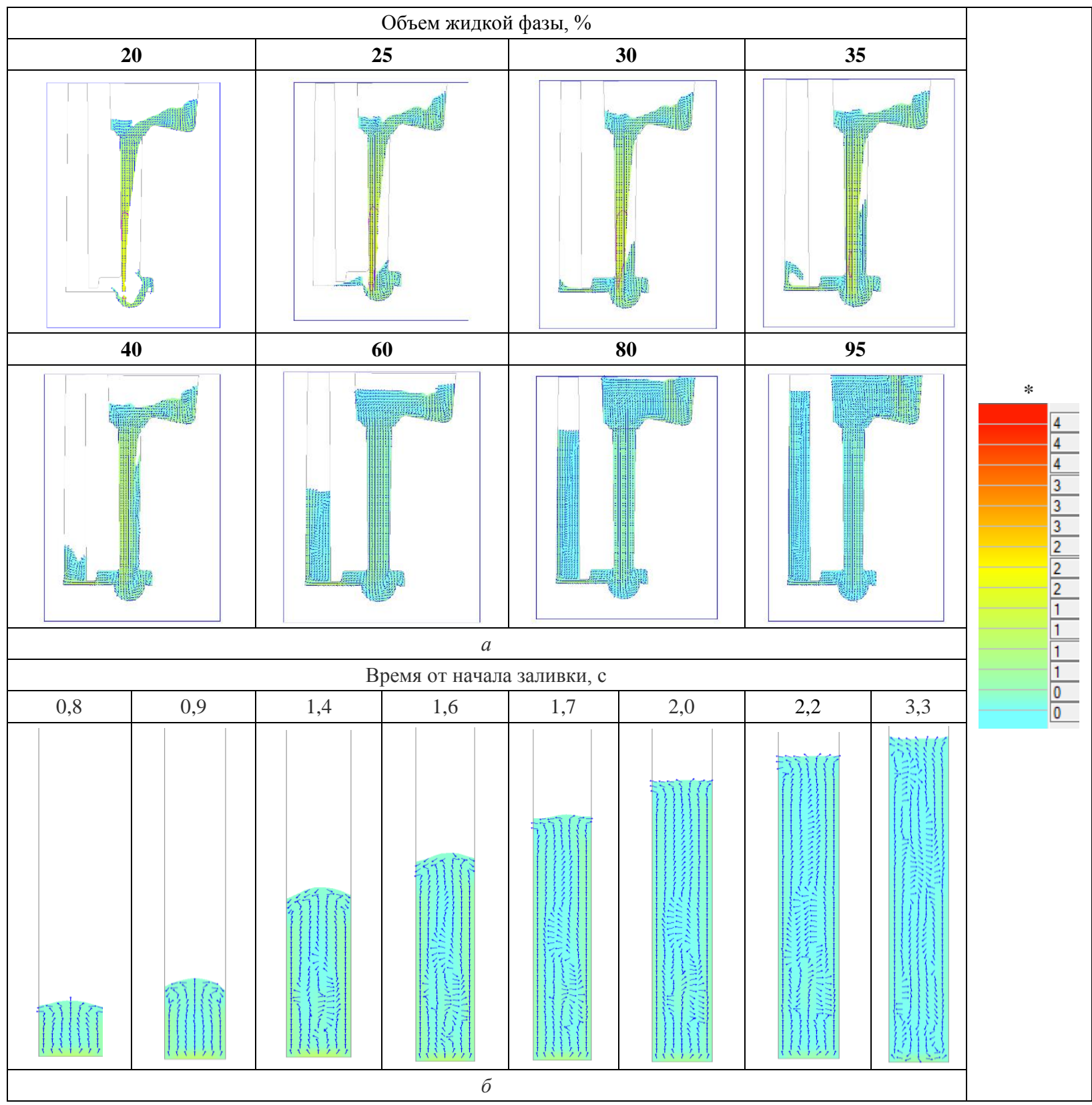

* - Цветовая идентификация скорости для потоков расплава, см/с.

Рис. 3. Изменения направлений индикаторов скорости течения расплава на характерных этапах последовательного заполнения расплавом песчаной формы:

$a$ - распределение потоков скоростей расплава при заполнении в продольном сечении для заготовки образца II и стояка с литниковой чашей; $\sigma$ - для заготовки образца II с фиксацией времени от начала заливки

В первые моменты после окончания заливки формы (т. е. прекращения динамического воздействия) конвективные потоки сохраняют направленность и скорость гидравлических потоков. Однако на 12 секунде (рис. 4, a) после начала заливки формируются отдельные и практически замкнутые циркулирующие контуры [8] расплава в объемах: литниковой чаши, вертикального стояка, центральной области литникового хода и отдельно в каждой заготовке образцов.

Снижение скорости конвективных потоков и их последующее затухание связывали с протеканием процесса кристаллизации отливки [9, $10,11]$ и увеличения содержания в объеме твердой фазы при сравнительном анализе соответствующих областей отливки (рис. 4, б) и времени от начала заливки формы расплавом. 


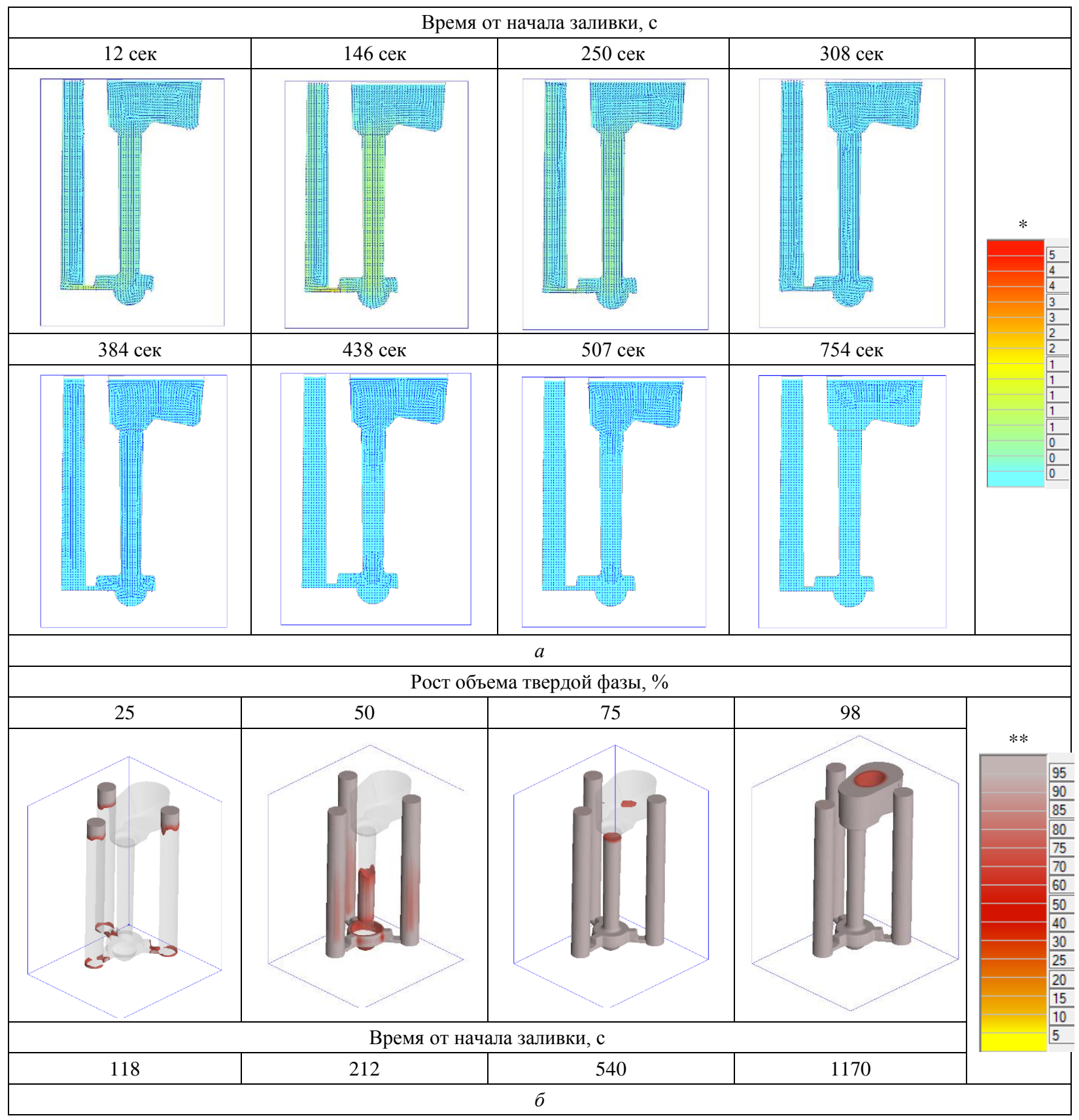

* - Цветовая идентификация скоростей для конвективных потоков расплава, см/с.

** - Цветовая идентификация объема твердой фазы при затвердевании, \%.

Рис. 4. Анализ периода кристаллизации формы с позиций:

$a$ - формирования конвективных потоков (распределение областей циркулирующего в различных объемах формы расплава с указанием направления индикаторами для продольного сечения заготовки образца II и стояка с литниковой чашей); $б$ - роста твердой фазы (режим отображения «прозрачная модель»)

На рис. 5 по данным компьютерного моделирования представлены этапы заполнения формы с цветовой идентификацией изменения значений температуры на поверхности соприкосновения расплава и стенки формы (без учета образца I), а также в продольном сечении заполненной формы для заготовки образца II и стояка с литниковой чашей (рис. $5, a$ ).
В первые моменты подачи расплава в объем формы среднее снижение температуры превышает $50 \ldots 70{ }^{\circ} \mathrm{C}$, и эта разность сохраняется практически постоянной $\left(1250{ }^{\circ} \mathrm{C}\right.$ на поверхности образца и $1320{ }^{\circ} \mathrm{C}$ в центральных зонах) до момента полного заполнения формы. Кроме этого, для нижней части литникового хода (рис. 5, б) показано, что при образовании запле- 
ска металла на стенке формы температура расплава может снижается до значений 1180$1150{ }^{\circ} \mathrm{C}$, что для использованных при моделировании в работе композиций чугуна является гра- ницами температур ликвидуса. Однако последующая подача расплава обеспечивает повышение температур до средней температуры расплава в нижней части области литникового хода.

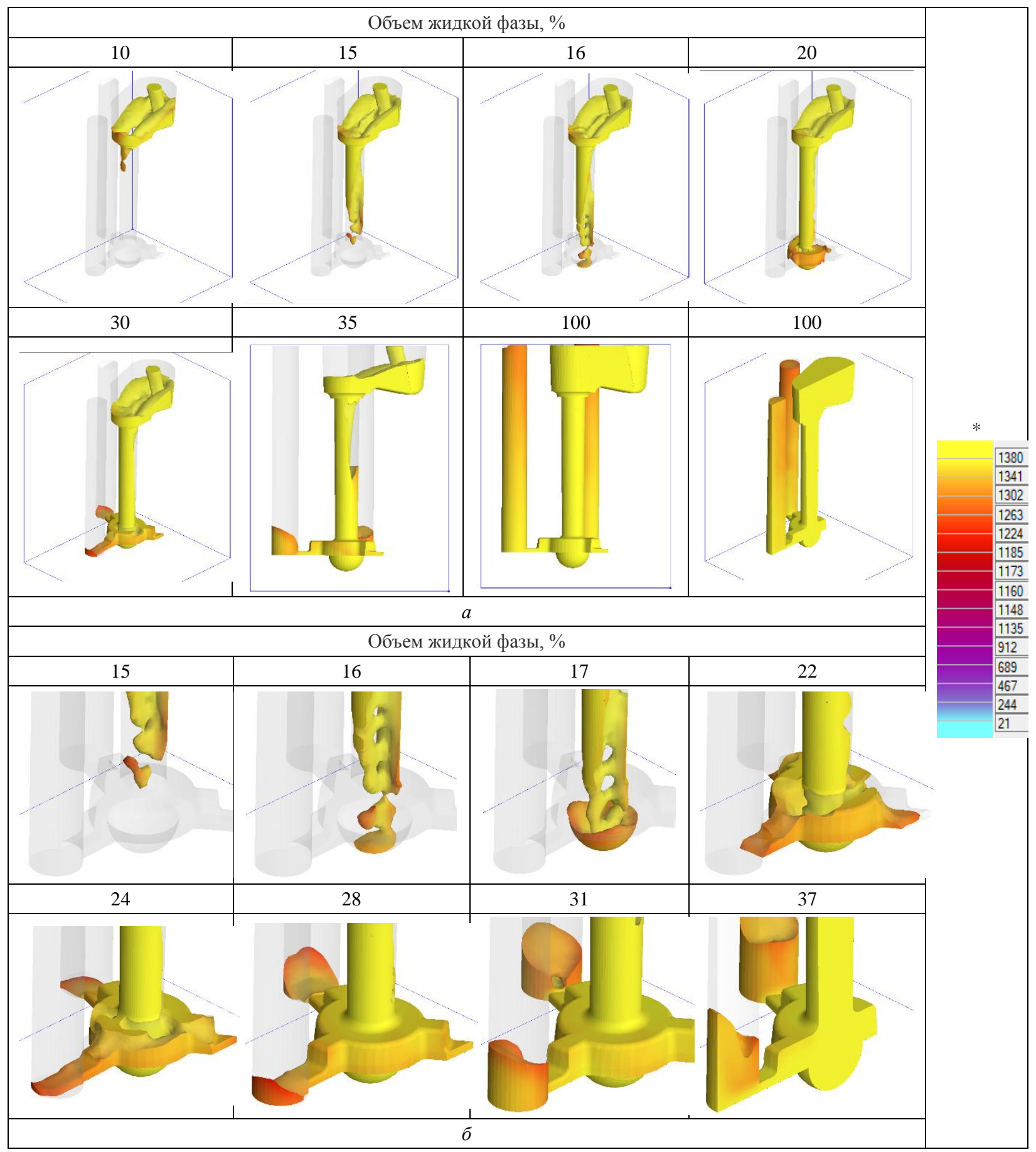

Рис. 5. Этапы заполнения формы с цветовой идентификацией изменения значений температуры* на поверхности соприкосновения расплава и стенки формы в режиме отображения «прозрачная модель»:

$a-$ без учета образца I и для продольного сечении заполненной формы для заготовки образца II и стояка с литниковой чашей; $\sigma$ - нижняя часть литникового хода

Охлаждение до $1100{ }^{\circ} \mathrm{C}$ центра всех трех образцов модели происходит за 610 секунд, а полное время кристаллизации всей отливки, включая литниковую чашу, происходит после 1124-й секунды моделирования. 


\section{Заключение}

Проведенное в работе компьютерное моделирование процесса заполнения расплавом песчаной формы для получения заготовок стандартных разрывных образцов для различных композиций серого чугуна марки СЧ20 позволило визуализировать основные этапы последовательного заполнения расплавом песчаной формы, образование гидравлических потоков расплава при заливке формы и конвекционных потоков при кристаллизации отливки. При этом показано, что переохлаждение расплава в момент образования заплеска не является критическим и не ведет к образованию литейных дефектов.

\section{БИБЛИОГРАФИЧЕСКИЙ СПИСОК}

1. ГОСТ 24648-90 Чугун для отливок. Отбор проб и изготовление образцов для механических испытаний. М. : Издательство стандартов, 2004. - 9 с.

2. ГОСТ 16818-85 Форма песчаная для получения заготовок образцов для испытания механических свойств серого чугуна с пластинчатым графитом. Размеры и технические требования - М.: Издательство стандартов, 2007. $10 \mathrm{c}$.
3. Барон, А. А. Компьютерное моделирование процессов заливки и затвердевания стандартных литых проб серого чугуна / А. А. Барон, Л. В. Палаткина, С. В. Палаткин // Известия ВолгГТУ : научный журнал № 2 (249) / ВолгГТУ. - Волгоград, 2021. - (Серия «Проблемы материаловедения, сварки и прочности в машиностроении»). - С. 64-71.

4. Марширов, В. В. Цифровые технологии при исследовании и управлении процессами изготовления отливок / В. В. Марширов, Л. Е. Марширова, И. В. Марширов // Литейное производство. - 2019. - № 9. - С. 34-38.

5. ГОСТ 1412-85 Чугун с пластинчатым графитом для отливок. Марки. - М.: Издательство стандартов, 2004. - 3 с.

6. Справочник по чугунному литью / под ред. Н. Г. Гиршовича - Л. : Машиностроение, 1978. - 758 с.

7. Рабинович, Б. В. Литниковые системы / Б. В. Рабинович // Вопросы теории литейных процессов. - М. : Государственное научно-техническое издательство машиностроительной литературы, 1960. - С. 110-162.

8. Еронько, С. П. Разливка стали : Оборудование. Технология / С. П. Еронько, С. В. Быковских. - К. : Техника, 2003. $-216 \mathrm{c}$.

9. Раддл, Р. У. Затвердевание отливок / Р. У. Раддл. М. : Машгиз, 1960. -390 с.

10. Баландин, Г. Ф. Основы теории формирования отливки : В 2 ч. / Г. Ф. Баландин. - Ч. 1. - М. : Машиностроение. 1979. -335 с.

11. Вейник, А. И. Основы тепловой теории литья/ А. И. Вейник // Вопросы теории литейных процессов. - М. : Государственное научно-техническое издательство машиностроительной литературы, 1960. - С. 385-482. 